Research Article

\title{
Effects of Foaming and Drainage Behavior on Structure and Properties of Polyurethane/Water Glass (PU/WG) Grouting Materials for Coal Mines
}

\author{
Xiaofeng Yu (D), Lizong Liu, Yuchao Wang, Guangfeng Bai, and Yu Zhang \\ Mine Materials Branch, China Coal Research Institute, China Coal Technology \& Engineering Group, Beijing 100013, China \\ Correspondence should be addressed to Xiaofeng Yu; yuxiaofeng_cup@163.com
}

Received 23 April 2021; Revised 23 June 2021; Accepted 1 July 2021; Published 14 July 2021

Academic Editor: Aboelkasim Diab

Copyright (C) 2021 Xiaofeng Yu et al. This is an open access article distributed under the Creative Commons Attribution License, which permits unrestricted use, distribution, and reproduction in any medium, provided the original work is properly cited.

\begin{abstract}
During the grouting operation in the underground coal mine, abnormal curing behaviors such as foaming and drainage often lead to the loss of reinforcement effect of the polyurethane/water glass (PU/WG) materials on coal walls and even cause safety accidents. Herein, three kinds of PU/WG grouting materials were successfully prepared by changing the type of catalysts, which were the normal sample (C7), the foaming sample (C14), and the sample with drainage (C17) during curing. The structure, thermal stability, and compressive strength of the three samples were characterized by scanning electron microscope (SEM), energy dispersive spectroscopy (EDS), X-ray diffraction (XRD), X-ray photoelectron spectroscopy (XPS), thermogravimetrydifferential thermal analysis (TG-DTA), and pressure testing machine. The results showed that the abnormal curing behavior had little effect on the thermal stability of the material, but it had a significant effect on the microstructure and compressive strength of the consolidated body. C7 exhibited a typical three-phase distribution, in which the polysilicate microspheres encapsulated by acicular carbonate were embedded in the polymer continuum. The structure of $\mathrm{C} 7$ had high rigidity and hardness, and the compressive strength was up to $43 \mathrm{MPa}$. The three-phase structure of $\mathrm{C} 14$ disappeared gradually with the increase of catalyst content, the hard block material and matrix are porous, and the compressive strength was only $2.7 \mathrm{MPa}$. The organic polymer of $\mathrm{C} 17$ existed in the form of microsphere and distributed irregularly in the continuum composed of inorganic components, and the compressive strength was $4.9 \mathrm{MPa}$. The abnormal solidification behavior such as foaming and drainage made the water glass/ polyurethane material lose its basic mechanical properties, which cannot meet the needs of grouting reinforcement in coal mines. Therefore, the type of catalyst had a significant impact on the stability of the system, and it is necessary to avoid selecting catalysts that are likely to cause abnormal solidification during formulation research.
\end{abstract}

\section{Introduction}

With the continuous deepening of coal mining, safety problems including roof fall and rib spalling often appear in the coal working face, which not only greatly reduce the mining efficiency but also threaten the life safety of miners $[1-3]$. Grouting plays an irreplaceable role in strengthening loose and broken coal and rock mass [4-12]. Grouting materials mainly include inorganic materials (clay $[13,14]$, water glass [15], cement [16-22], etc.), organic materials (polyurethane [23, 24], phenolic resin, epoxy resin [25-28], etc.), and composite materials (polymer/cement [29-31], epoxy resin/cement, polyurethane/water glass [32, 33], etc.).
Inorganic materials have some disadvantages, such as slow curing time, low bond strength, difficulty to penetrate the tiny cracks in coal and rock mass due to large slurry size, which make it difficult to be applied in the coal mining face that requires timeliness. The high reaction exotherm, flammability, and high cost of the organic materials violate the original intention of the disaster management. In addition, organic materials are easy to foam in wet cracks $[34,35]$, and the strength decreases greatly. Silicate modified polyurethane material (PU/WG) served as an organic-inorganic hybrid composite system, which overcomes the inherent shortcomings of the polyurethane system, and not only has the advantages of water glass and polyurethane, 
such as low cost, good flame retardancy, large diffusion radius, and high bonding strength but also has the outstanding advantages of less heat release and high early strength. Furthermore, PU/WG material is brittle, which is not only conducive to the shearer cutting coal but also beneficial for the roadway expanding and shed changing. PU/WG composite grouting material has been widely used in coal mines due to its many advantages.

PU/WG grouting materials have obtained many research achievements, which mainly focused on material development, performance research, and engineering application. $\mathrm{He}$ et al. investigated the effect of silane on the compressive strength of the PU/WG composites [32]. Zhang et al. studied the influence of different catalysts on the structure and properties of the PU/WG materials [33]. However, there is almost no research on the influence of abnormal curing behaviors such as foaming and drainage on the structure and mechanical properties of the PU/WG materials, which occur in underground coal mine construction sites. The materials leaking out of the coal wall tend to form foaming and drainage phenomena, resulting in poor reinforcement effects and even collapse of the coal wall.

The current research on the abnormal curing behaviors of foaming and drainage analysis involved the microstructure of the material, but almost no one pays attention to the influence on the structure and mechanical properties of the material. Polyurethane/water glass is an organicinorganic composite two-component grouting material, one of which is almost completely inorganic sodium silicate solution, and the other is mainly isocyanate. The main reactions involved include the reaction of isocyanate with water to form $\mathrm{CO}_{2}$ (foaming reaction), sodium silicate solution to absorb $\mathrm{CO}_{2}$ to generate carbonate, and isocyanate to react with silicic acid polymer (gel reaction). These reactions proceed at the same time and interact with each other to form a consolidated substance. The formation process of consolidated materials is very complex, including interpenetration, coupling, and phase transition of organic and inorganic structures. Therefore, the reaction of foaming and gelation reaches equilibrium, and the distribution of the phase of the consolidated body is the prerequisite for the excellent mechanical strength of the material. The behaviors such as foaming and drainage during the reaction inevitably lead to changes in structure and performance.

Herein, three kinds of PU/WG grouting materials were prepared by adjusting and controlling the catalyst, which were the normal samples, the foaming samples, and the samples with drainage during curing. In order to investigate the influence of the abnormal curing behaviors deeply and thoroughly on the structure and properties of the PU/WG grouting materials, the structures of three samples were analyzed, and the thermal stability and compressive strength were compared. The study is helpful to understand the characteristics of the water glass/polyurethane system and provides a reference for the subsequent catalyst screening and formulation research. At the same time, it is of guiding significance for on-site construction; strictly controlling the grouting process; avoiding foaming, drainage, and other phenomena; achieving the reinforcement effect; and ensuring the safety of coal mining.

\section{Experiments}

2.1. Materials. All the catalysts and additives and the plasticizer used in this study were purchased from commercial suppliers (Shanghai Aladdin Biochemical Technology Co., Ltd., Shanghai, China) and were used without further purification. Polymethylene polyphenylisocyanate (PM200, NCO content 30.5-32.0\%; Yantai Wanhua Polyurethane Co., Ltd., Shandong, China), polyether polyol (DL2000D, hydroxyl value (mg KOH/g): 54.5-57.5; Shandong Lanxing Dongda Chemical Co., Ltd., Shandong, China), and WG (Baume degree 50, modulus 2.6; Jingliangui New Materials Co., Ltd., Shandong, China) were used as main raw materials. Glycerol and dioctyl phthalate (DOP) were utilized as the additive and plasticizer, respectively.

2.2. Preparation of PU/WG Grouting Materials. Grouting materials are generally composed of organic and inorganic components. The composition of PU/WG grouting materials is listed in Table 1.

Component A (inorganic component): first, a certain amount of catalyst and additives was fully mixed. Then, it was added slowly to the WG stirred vigorously. The resulting mixture was uniformly stirred at a speed of $800 \mathrm{rpm}$ for $15 \mathrm{~min}$.

Component B (organic component): PM200 and DL2000D were added to the reactor, respectively, and the prepolymer was prepared at $80^{\circ} \mathrm{C}$ for 2 hours. After that, DOP and the prepolymer were stirred in the same manner. The obtained mixture was cooled to room temperature and then sealed in a dry container.

2.3. Preparation of Curried Samples. As shown in Figure 1, components $\mathrm{A}$ and $\mathrm{B}$ were mixed and stirred with the volume ratio of $1: 1$ at $800 \mathrm{rpm}$ for $15 \mathrm{~s}$. Then, slurry obtained was quickly poured into the mold (cylinder: diameter is $50 \mathrm{~mm}$, and height is $100 \mathrm{~mm}$ ) coated with a release agent. After the samples became obviously hard, they were taken out from the mold, and the compressive strength was tested after aging at room temperature for 3 days.

2.4. Materials Characterization. The curing time was measured at a temperature of $20^{\circ} \mathrm{C} .50 \mathrm{~mL}$ of component $\mathrm{A}$ and $50 \mathrm{~mL}$ of component $\mathrm{B}$ were poured into a disposable plastic cup and then stirred at a constant speed of $15 \mathrm{~s}$. The time from the beginning of stirring to the curing of the materials is recorded. The endpoint was determined according to the reported literature [33]. Compressive strength curves were conducted using the automatic servo pressure testing machine (YAW-300B provided by Testing Technology Co., Ltd). The loading speed was $5 \mathrm{~mm} / \mathrm{min}$, and the condition of crushing was set to $5 \%$ of the peak value. Compressive strength testing was performed according to the GB/T25672008 standard [36]. Scanning electron microscopy (SEM) 
TABLE 1: Compositions of the PU/WG grouting materials.

\begin{tabular}{lccc}
\hline & Composition & Amount $(\mathrm{g})$ & Main property \\
\hline \multirow{3}{*}{ Component A } & WG & 100 & Modulus: 2.6 Baume degree $\left(20^{\circ} \mathrm{C}\right): 49.5 \pm 0.5$ \\
& Glycerin & 1.5 & - \\
\hline \multirow{3}{*}{ Component B } & Catalyst & $0-1$ & NCO content (\%): $30.5-32.0$ \\
& PM200 & 90 & Hydroxyl value (mg KOH/g): $54.5-57.5$ \\
\hline
\end{tabular}

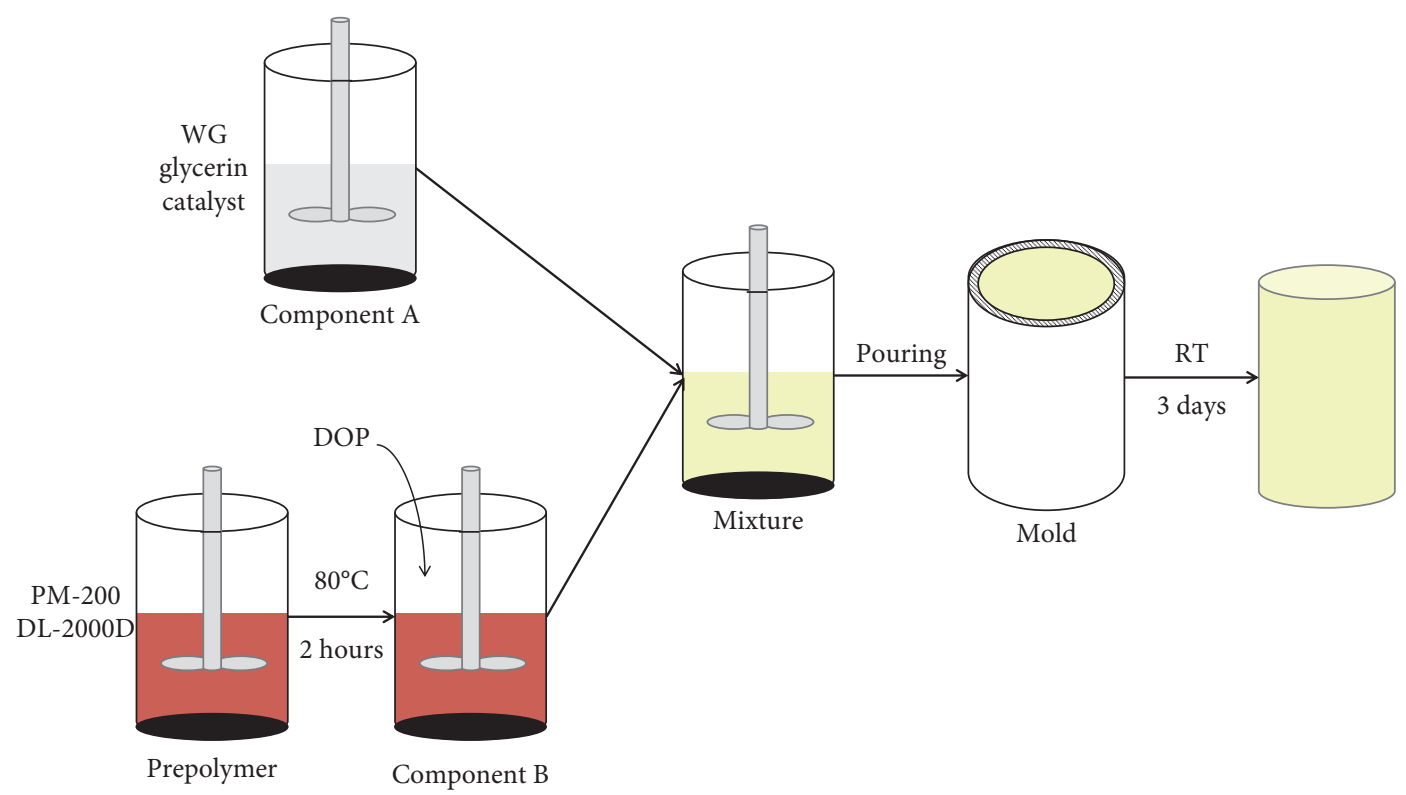

Figure 1: Schematic illustration of the preparation of the PU/WG components and curried samples.

pictures were obtained using a Hitachi S4800. X-ray diffraction (XRD) patterns were measured on a Bruker D8 Advanced diffractometer $(40 \mathrm{kV}, 40 \mathrm{~mA})$ using $\mathrm{Cu}-\mathrm{Ka}$ radiation (wavelength $\lambda=1.5406 \AA$ ) from 15 to $60^{\circ}$ at a scanning rate of $8^{\circ} / \mathrm{min}$. Thermogravimetric analysis (TGA) was collected from a NETZSCH STA449F5 with a heating rate of $10^{\circ} \mathrm{C} / \mathrm{min}$ under a flow of $100 \mathrm{~mL} / \mathrm{min}$ Nitrogen. $\mathrm{X}$-ray photoelectron spectroscopy (XPS) curves were collected from Perkin Elmer Spectrum 100.

\section{Results and Discussions}

3.1. The Performance and Selection of Catalysts. The catalytic properties of 26 kinds of organic amine catalysts for PU/WG grouting materials were investigated. According to the state of the consolidated body after the reaction, the samples can be divided into three categories: the samples with normal curing process, the samples with drainage on the surface of the material during curing, and the samples with foaming during curing. No. 7, No. 14, and No. 17 (the molecular structure is inlaid in Figure 2) catalysts were selected for the PU/WG grouting process, corresponding to the curing process of normal, foaming, and drainage, respectively. Therefore, the three catalysts were selected for subsequent experiments. As shown in Figure 2, the curing time was obviously shortened with the increase of the additional

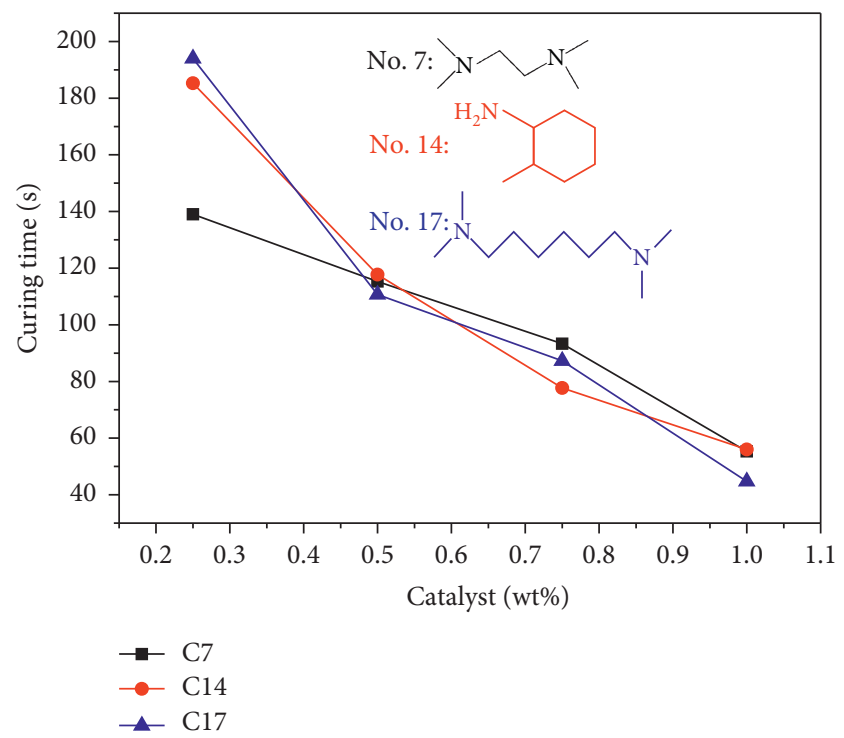

Figure 2: Curing time of samples catalyzed by different types and additive number of catalysts.

amount. When the addition amount was $0.25 \%$, the catalytic activity of $\mathrm{C} 7$ was much higher than that of $\mathrm{C} 14$ and $\mathrm{C} 17$. However, when the addition amount was $1 \%$, the catalytic efficiency of $\mathrm{C} 17$ was the highest, and the curing time was 
$44.7 \mathrm{~s}$. There are the same functional groups and the different lengths of carbon chain in the C7 and C17 structure, and the activity of the two catalysts was obviously different.

3.2. Morphology and Composition Analysis. The morphologies of the PU/WG samples catalyzed by three catalysts are shown in Figure 3. The samples were cured normally under different dosages of the $\mathrm{C} 7$ catalyst, and there was no obvious difference in appearance. When the content of C14 was $0.25 \%$, the appearance and texture of the samples were similar to those obtained by $\mathrm{C} 7$ catalysis. When the content of C14 was 1\%, the sample foamed seriously, and the volume was about twice that of the normal sample. The isocyanate first reacted with the water in the water glass to release $\mathrm{CO}_{2}$ under the action of catalyst, and the rate of $\mathrm{CO}_{2}$ absorption by silicate was less than the release rate; that is, the gel rate was less than the foaming rate, which eventually led to a larger volume of the consolidation and a loose and porous structure. The sample showed drainage phenomenon during the curing process, which was catalyzed by different amounts of C17. The small droplets gradually precipitated on the surface of the material after the slurry was mixed and solidified, and the number of small droplets increased and finally converged on the surface of the material. The precipitated liquid turned into white powder in a few minutes at room temperature. As can be seen from Figure 2, the larger the amount of catalyst was added, the whiter the powder adhered on the surface of the sample, indicating that the more liquid separated during curing. The surface of the C7$1 \%$ sample was smooth, glossy, and white. The color of the C14-1\% sample was yellow, and the texture was loose and porous. The surface of the C17-1\% sample was covered with a lot of white powder, and the color was yellow. Therefore, the type and amount of catalyst not only changed curing time but also had a significant effect on the morphology of samples. This may be ascribed to the fact that different agents had different catalytic tendencies towards foaming reaction and gel reaction of the PU/WG hybrid system, or the foaming reaction and gel reaction were not balanced.

XRD characterization was carried out to determine the main components of white powder with $\mathrm{C} 17-1 \%$ precipitation as shown in Figure 4. According to jade software analysis, the main component of white powder with $\mathrm{C} 17-1 \%$ precipitation is $\mathrm{Na}_{3} \mathrm{H}\left(\mathrm{CO}_{3}\right)_{2} \cdot 2 \mathrm{H}_{2} \mathrm{O}$.

\subsection{Structural Analysis}

3.3.1. C7-1\% Sample. The cross section morphology of the C7-1\% sample is shown in Figure 5 and the C7-1\% sample is composed of the continuous phase, microsphere phase, and connecting phase. The microspheres of different sizes are embedded in a continuous phase irregularly, and the surface of the crater is covered with another substance. The C7-1\% sample was analyzed by energy dispersive spectrometer (EDS) to determine the distribution of elements in the threephase structure, and the enrichment rules of $\mathrm{C}, \mathrm{N}, \mathrm{O}, \mathrm{Na}$, and $\mathrm{Si}$ were mainly characterized. Figure 6 shows the mapping distribution of elements. Almost all $\mathrm{C}$ elements were distributed in the continuous phase, while $\mathrm{O}$ elements were distributed in the continuous phase and microsphere. At the same time, Si elements were concentrated in the microsphere area, while $\mathrm{Na}$ did not show apparent regularity. It is preliminarily inferred that the continuous phase and microsphere may be polyurethane polymer phase and siloxane compounds, respectively.

The atomic ratio of elements in each phase was scanned by EDS for quantitative analysis. As shown in Figure 7, the elements with high atomic content in the microsphere region (region 1) are $\mathrm{O}$ and $\mathrm{Si}$, and the atomic percentage is 3 : 2. It is speculated that the microsphere phase is silicate polymer, not silica. There are a lot of $\mathrm{C}, \mathrm{N}$, and $\mathrm{O}$ elements in zone 2, which are mainly polyurethane phases. The main elements in region 3 are $\mathrm{Na}, \mathrm{C}$, and $\mathrm{O}$, and the corresponding atomic ratio is $10: 43: 41$. It is speculated that region 3 may contain both $\mathrm{Na}_{2} \mathrm{CO}_{3}$ and polyurethane, which is in a transition state structure.

The element state of the C7-1\% sample was characterized by XPS, and there were $\mathrm{Na}, \mathrm{Si}, \mathrm{C}, \mathrm{O}$, and $\mathrm{N}$ elements in Figure 8 . There was no $\mathrm{Si}-\mathrm{C}$ bond in the $\mathrm{Si} 2 \mathrm{p}$ spectrum, and the peak at $103.6 \mathrm{eV}$ was attributed to the characteristic peak of silicate polymer, corresponding to $\mathrm{Si}^{4+}$. The peaks at 531.9 and $533.4 \mathrm{eV}$ belong to the characteristic peak of Si-O and $\mathrm{C}=\mathrm{O}$, respectively, and the peak at $535.9 \mathrm{eV}$ was derived from the interference peak of $\mathrm{Na}$. The peaks at 284.8, 286.0, and $289.8 \mathrm{eV}$ in $\mathrm{C} 1 \mathrm{~s}$ spectra were assigned to the characteristic peaks of C-C, C-O-C, and $\mathrm{Na}_{2} \mathrm{CO}_{3}$. There was no $\mathrm{Si}$ $\mathrm{C}$ bond between the microspheres and the polymer carbon chain, and the microspheres were only filled in the polymer continuum in the form of physical filling. In addition, XPS spectra further confirmed the EDS results.

3.3.2. C14 Sample. Figure 9 shows the SEM images of C14 samples with different additions of C14 catalyst. C14-1\% sample produced foaming, and there were small block-like and rod-shaped crystals stacked on the surface of the porous matrix, but no microspheres. There is a porous structure on the surface of the small block-like crystal, while the rodshaped crystal is composed of lamellar stacking and dense texture. However, there are disorderly distributed rodshaped crystals in the C14-0.75\% sample, and small blocklike crystals disappear. With the decrease of catalyst content, the foaming degree of the material decreased, and microspheres gradually appeared in the C14 sample (as shown in Figure 9 (C2)). Besides, the composition of the C14-0.25\% sample is similar to that of the $\mathrm{C} 7$ sample.

The EDS results of the $\mathrm{C} 14-1 \%$ sample are shown in Figure 10. Si and $\mathrm{O}$ elements were enriched on the surface of the matrix, and a large amount of $\mathrm{Na}$ and $\mathrm{O}$ elements was contained in the stacking materials on the surface, while there is no obvious concentration area of the $\mathrm{C}$ element. The molecular structure of No. 14 catalyst contains primary amine, which acted as a nucleophilic reagent to attack the NCO group in isocyanate to form an intermediate complex, and the complex reacted with active hydrogen in water to release $\mathrm{CO}_{2}$ [33]. A large number of $\mathrm{CO}_{2}$ cannot be absorbed by silicate solution in time, and no rigid structure was 


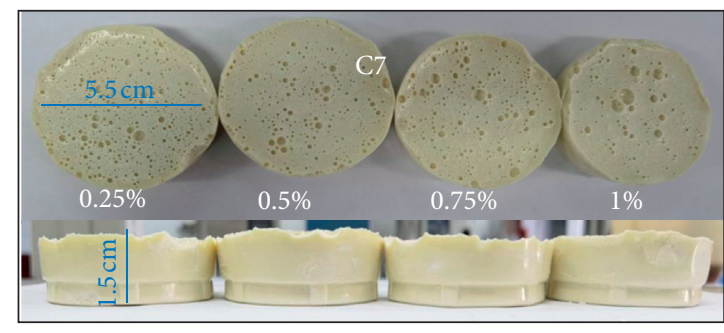

(a)

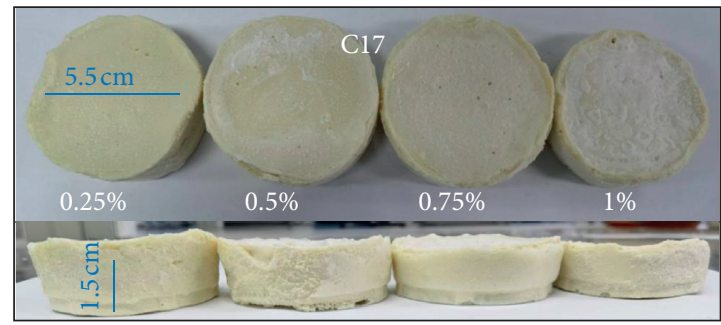

(c)

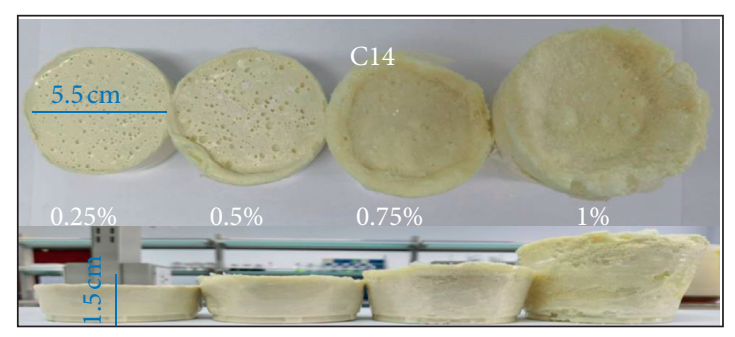

(b)

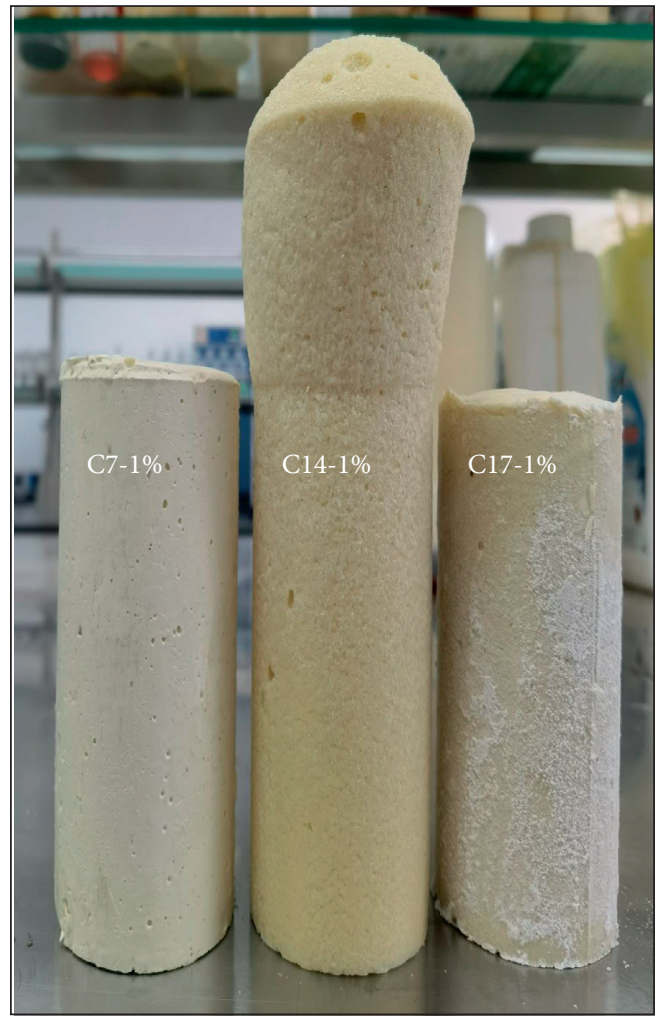

(d)

FIGURE 3: The morphologies of samples catalyzed by different types and additive number of catalysts.

formed in the system simultaneously. The final sample existed in foam form with the release of $\mathrm{CO}_{2}$.

\subsubsection{C17-1\% Sample. SEM images of the C17-1\% sample} are shown in Figure 11, which are similar to those of C7-1\%, with microsphere and continuous phase. There was no connecting phase on the surface of the ball pit. The surface of the microspheres is smooth and wrinkled, and the diameter is large, even up to $200 \mathrm{um}$. Besides, the continuous phase contains a large number of micropores.

The EDS results of the $\mathrm{C} 17-1 \%$ sample are quite different from those of $\mathrm{C} 7-1 \%$ (Figure 12). C was almost completely concentrated in the microsphere region, while $\mathrm{Si}$ and $\mathrm{O}$ atoms were concentrated in the continuous phase. The low content of $\mathrm{Na}$ is attributed to the large amount of $\mathrm{Na}$ precipitated out of the solution. EDS-dot scanning results showed that the microsphere region was an organic phase, the total number of $\mathrm{C}, \mathrm{N}$, and $\mathrm{O}$ atoms accounted for $99.54 \%$, and the total number of $\mathrm{Si}$ and $\mathrm{O}$ atoms in region 2 accounted for about $77 \%$. Therefore, the microstructure of $\mathrm{C} 17-1 \%$ is opposite to that of $\mathrm{C} 7-1 \%$, and polyurethane exists in the form of microspheres.

3.4. Thermal Stability Analysis. The samples were characterized by TG-DTA to analyze the thermal stability and composition differences of the three samples, as shown in Figure 13. The TG curves of the C7-1\% and C17-1\% samples are similar in Figure 13(a), indicating that the two samples had a similar material composition. Comparing Figures 13(b) and 13(d), the two samples had an obvious exothermic peak from room temperature to $120^{\circ} \mathrm{C}$, which is mainly ascribed to the unreacted water in the water glass raw material and the water adsorbed on the material surface. The weight loss of the $\mathrm{C} 7-1 \%$ and $\mathrm{C} 17-1 \%$ samples is $22 \%$ and $20 \%$, respectively. The water content of the C17-1\% sample is relatively low, which may be caused by the loss of part of water during drainage. In addition, there are obvious exothermic peaks between $300^{\circ} \mathrm{C}$ and $350^{\circ} \mathrm{C}$, which was due to 


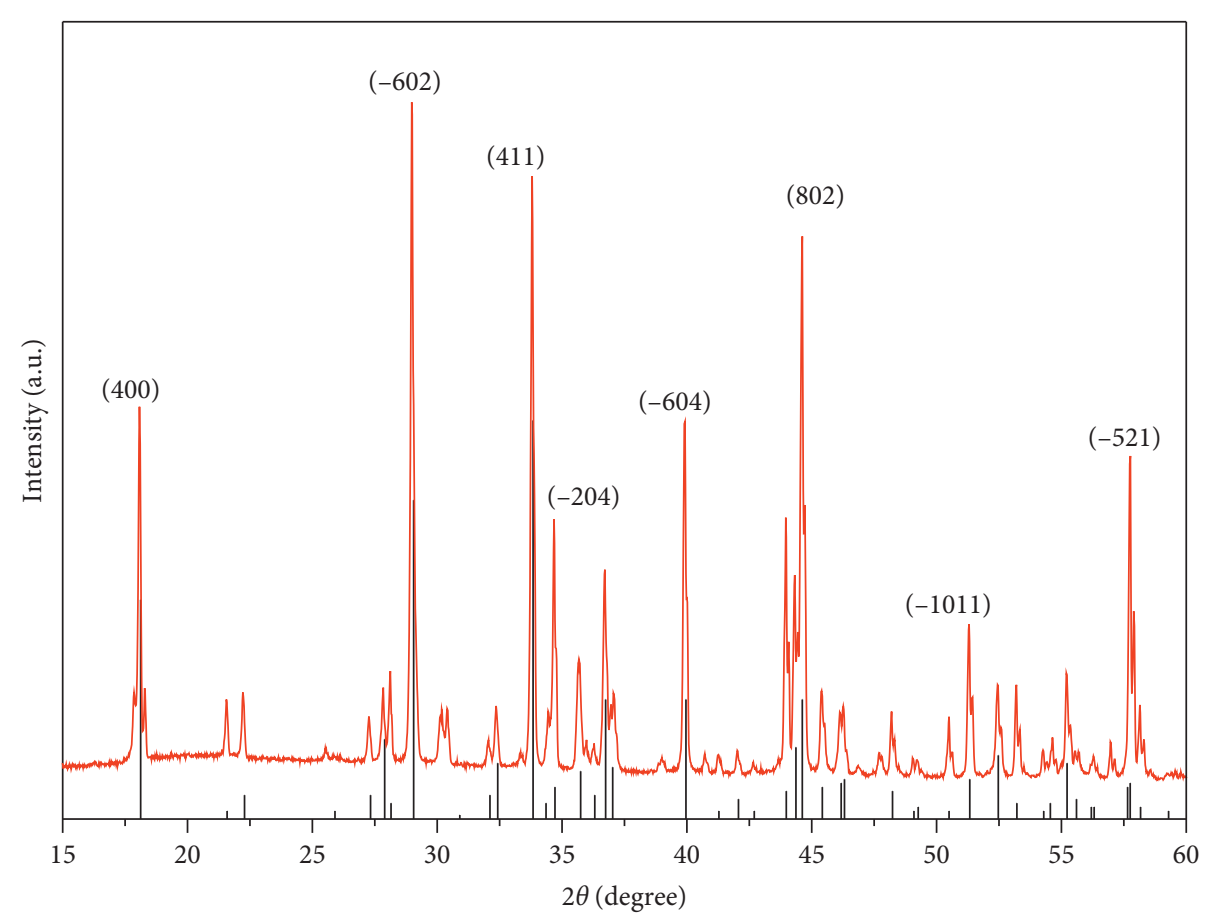

- White powders with $\mathrm{C} 17-1 \%$ precipitation

$-\mathrm{Na}_{3} \mathrm{H}\left(\mathrm{CO}_{3}\right)_{2} \cdot 2 \mathrm{H}_{2} \mathrm{O}$

FIGURE 4: XRD patterns of precipitation in the C17-1\% samples.

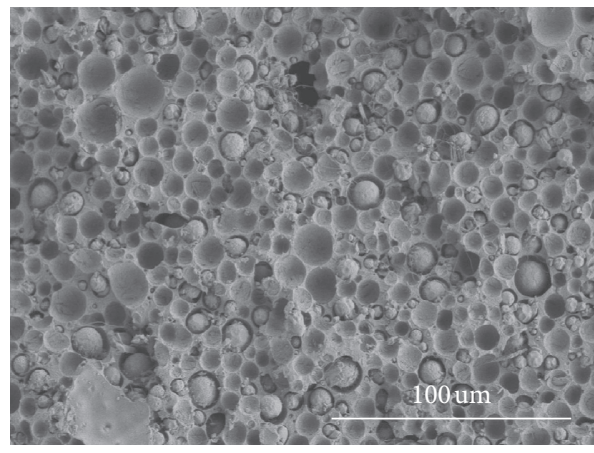

(a)

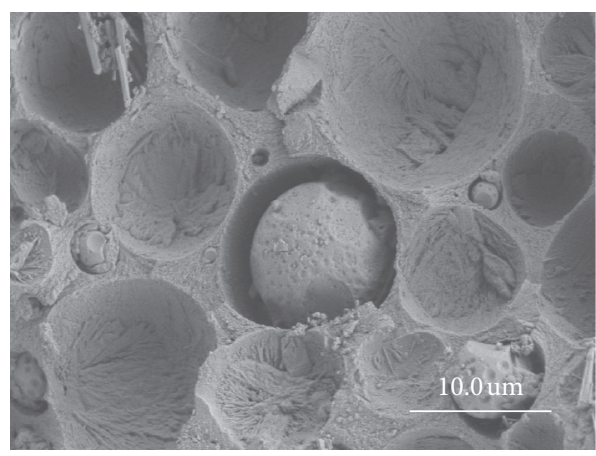

(c)

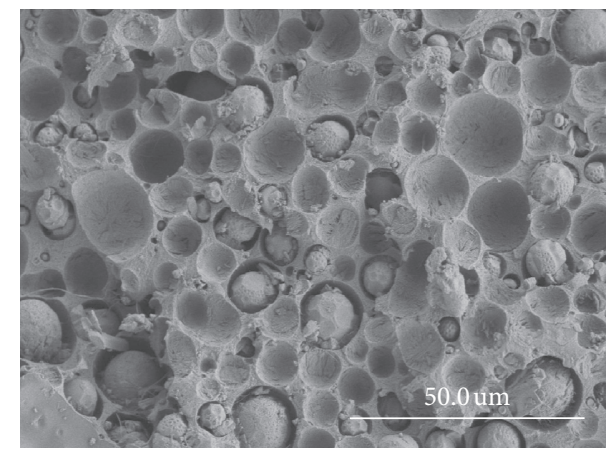

(b)

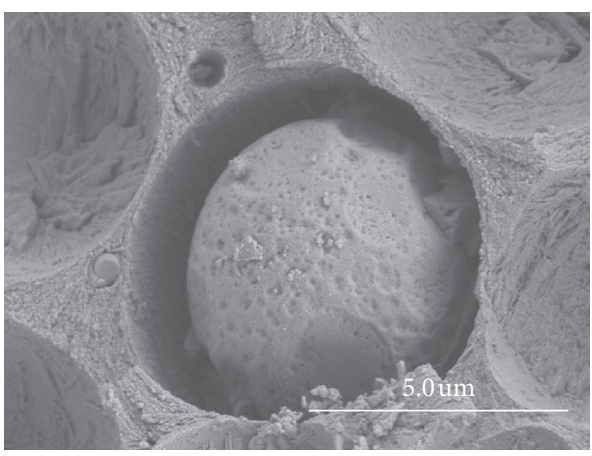

(d)

FIGURE 5: SEM images of the C7-1\% sample: (a) 500x, (b) $1000 x$, (c) $3000 x$, and (d) $6000 x$. 

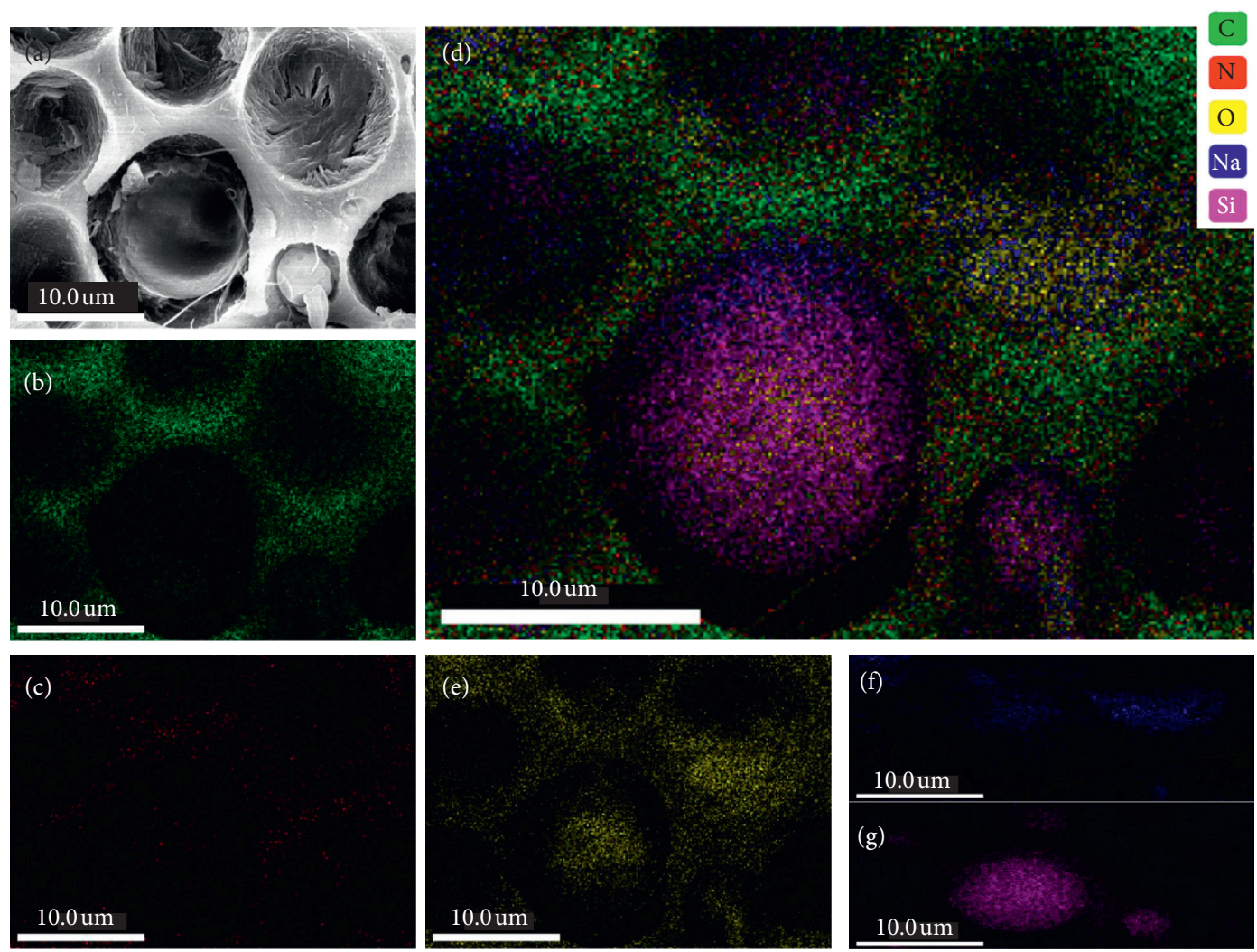

Figure 6: Element distribution of the C7-1\% sample.

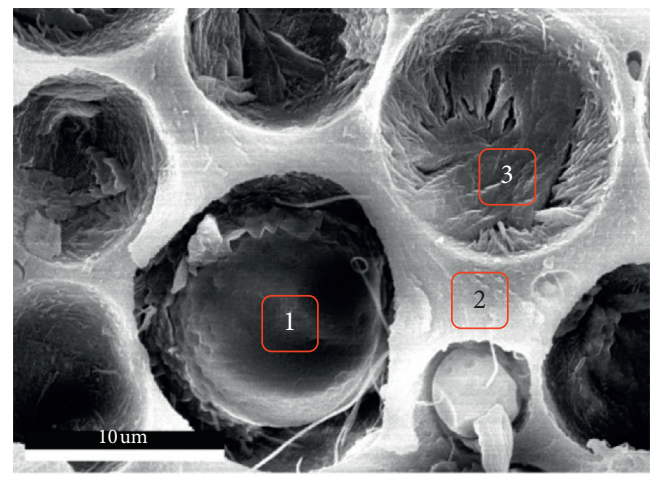

(a)

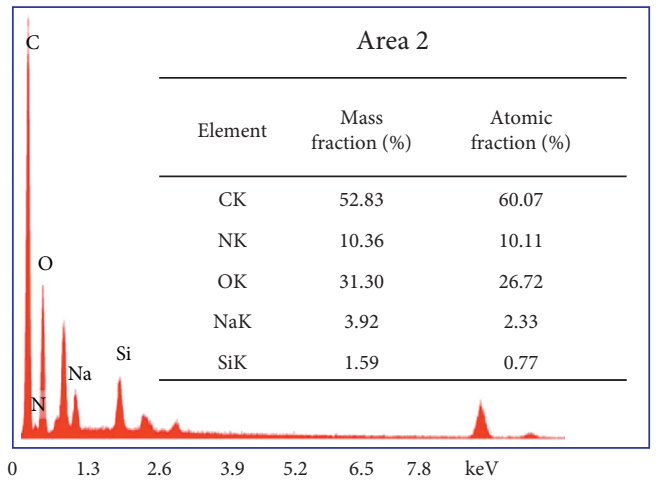

(c)

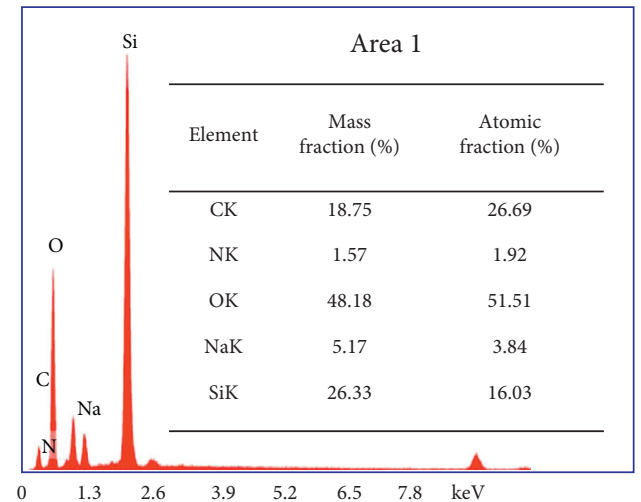

(b)

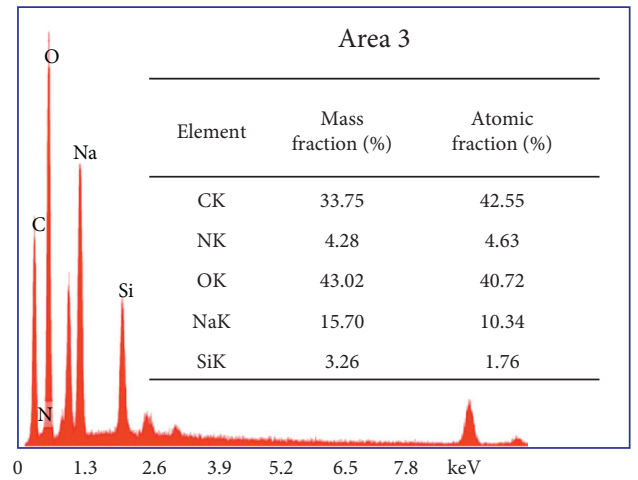

(d)

Figure 7: The morphologies of samples catalyzed by different types and additive number of catalysts. 

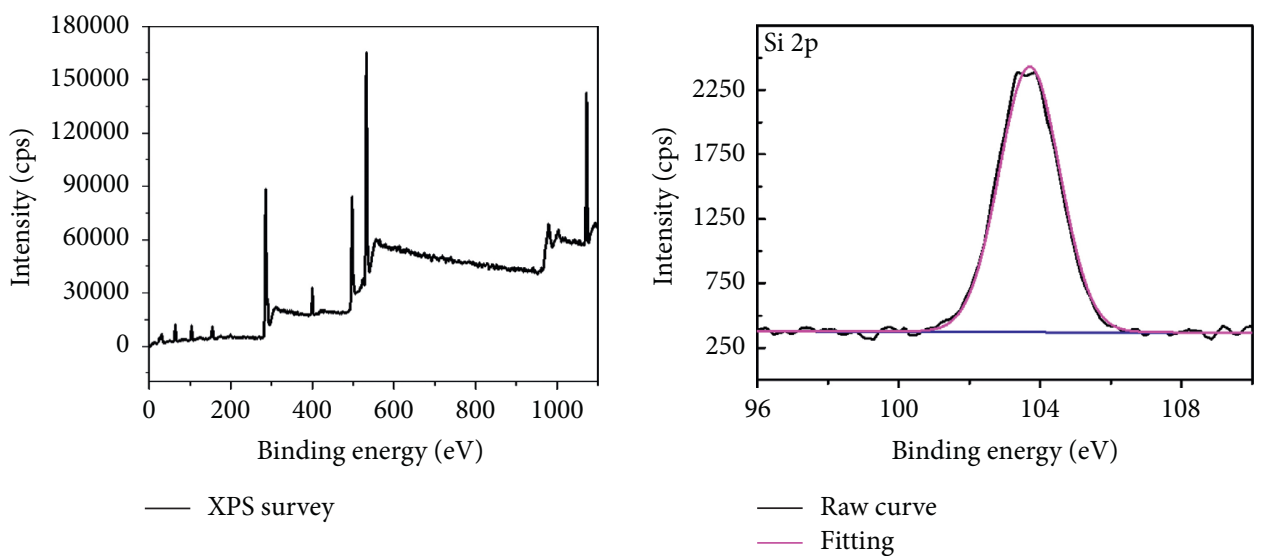

(a)

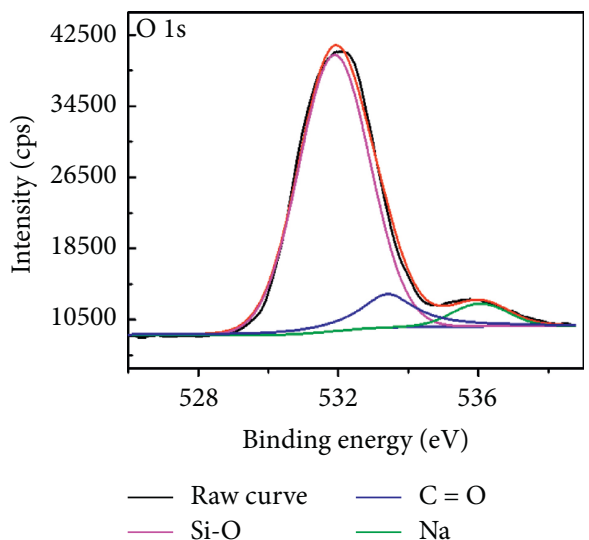

(c)

(b)

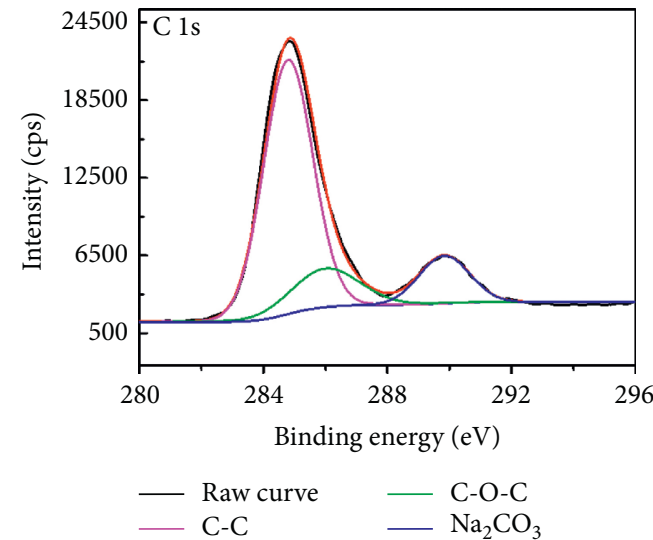

(d)

Figure 8: XPS spectra of the C7-1\% sample.
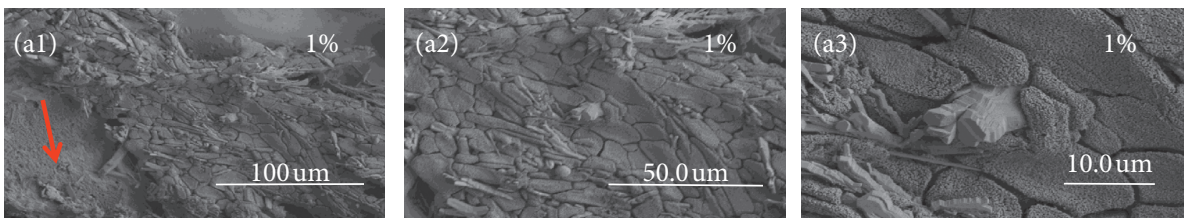

(a)
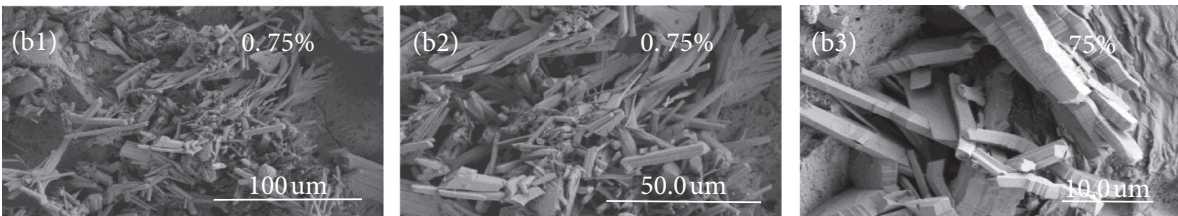

(b)
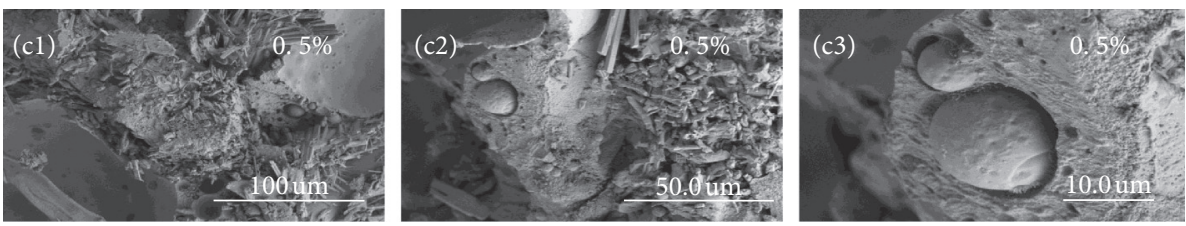

(c)

FIgURE 9: Continued. 

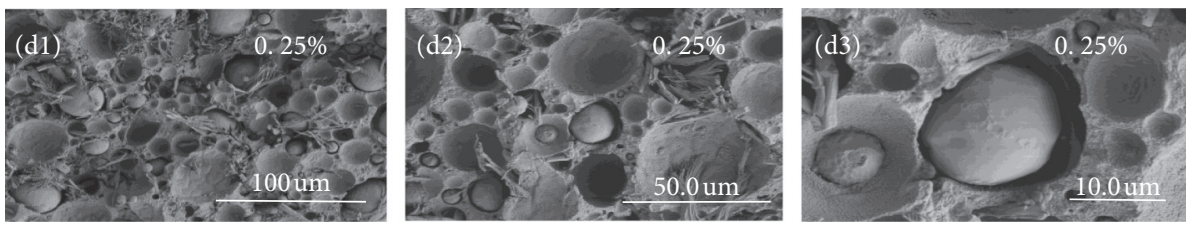

(d)

Figure 9: SEM images of the C14 samples: (a) C14-1\%, (b) C14-0.75\%, (c) C14-0.5\%, and (d) C14-0.25\%.
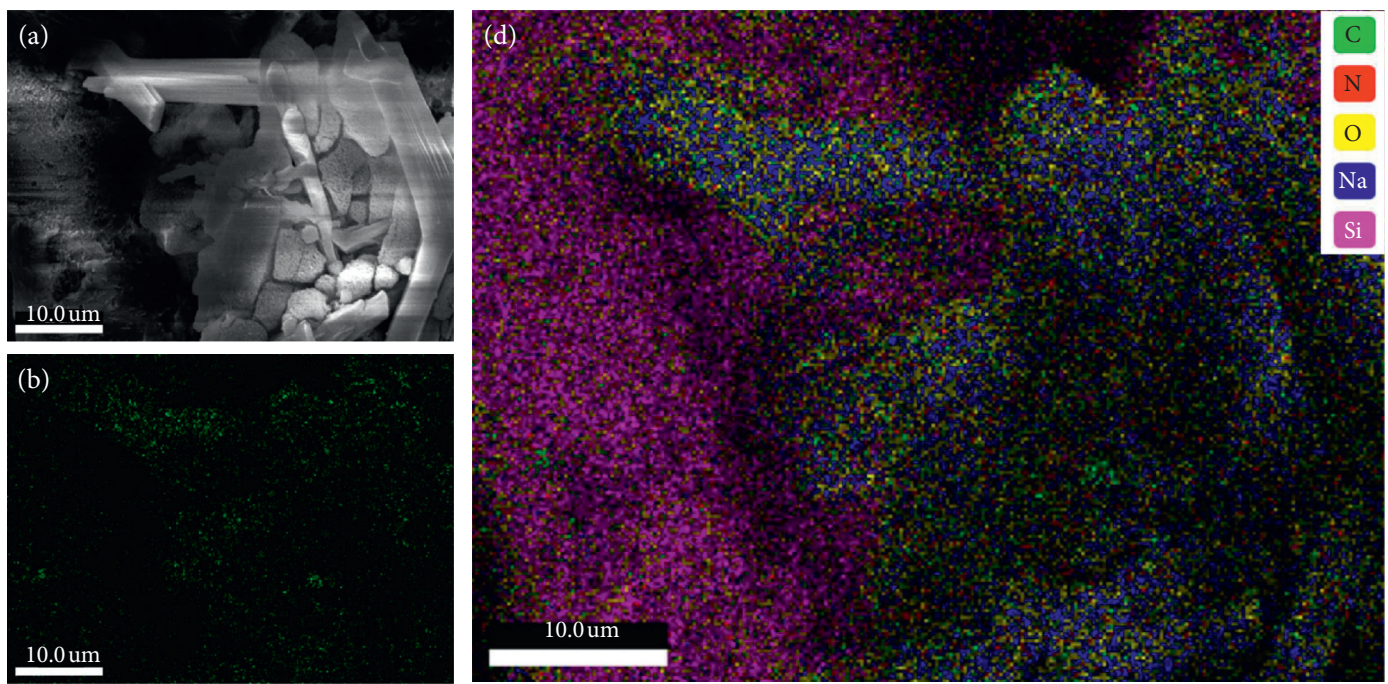

$10.0 \mathrm{um}$
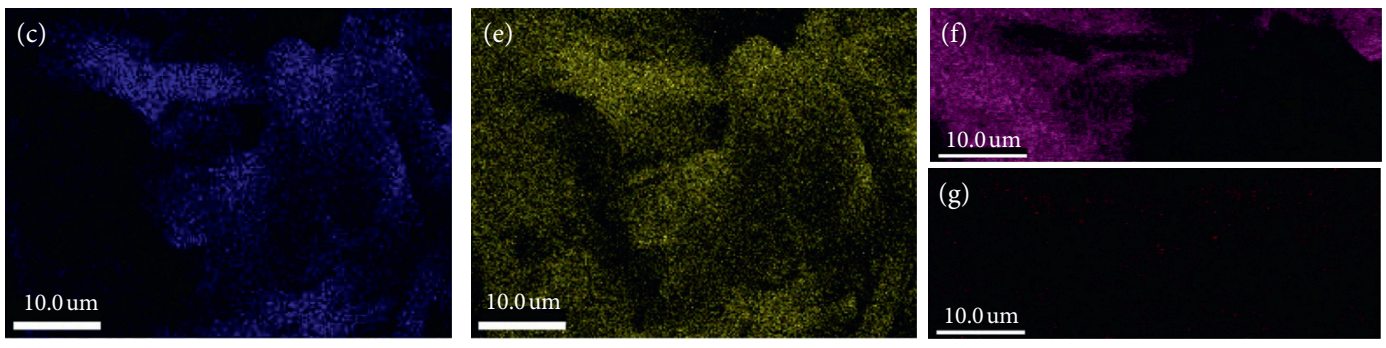

$10.0 \mathrm{um}$

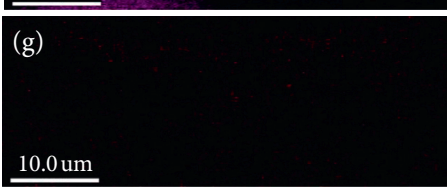

Figure 10: Element distribution of the C14-1\% samples.

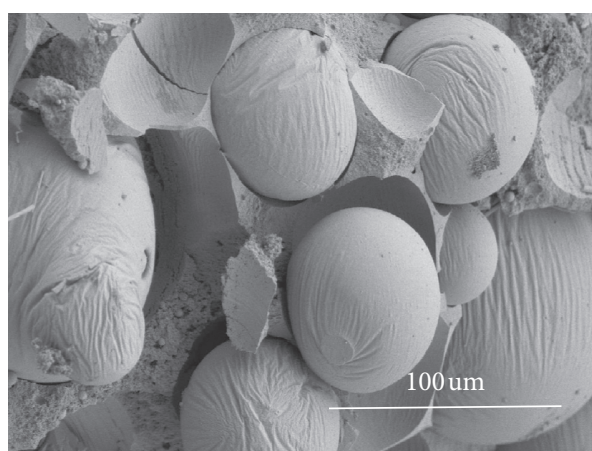

(a)

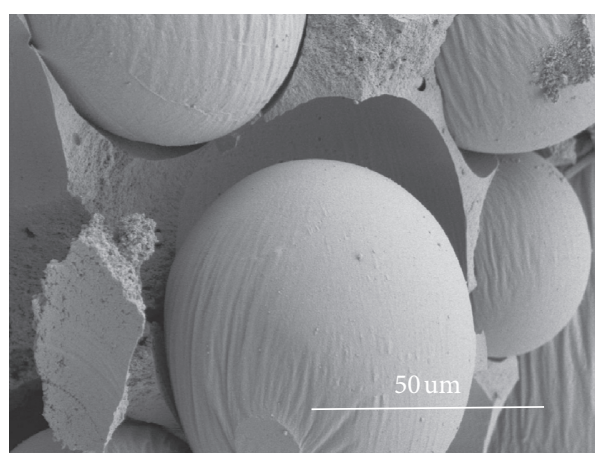

(b)

FIGURE 11: Continued. 


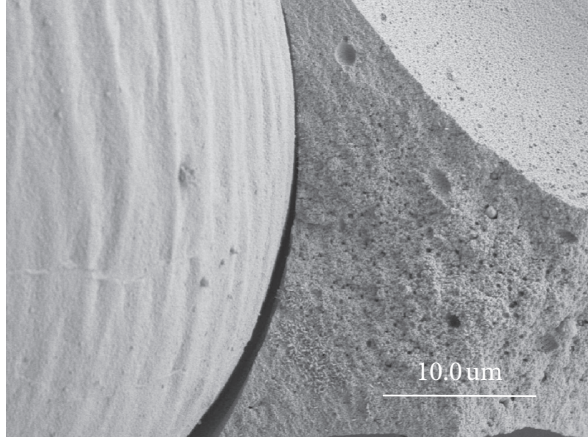

(c)

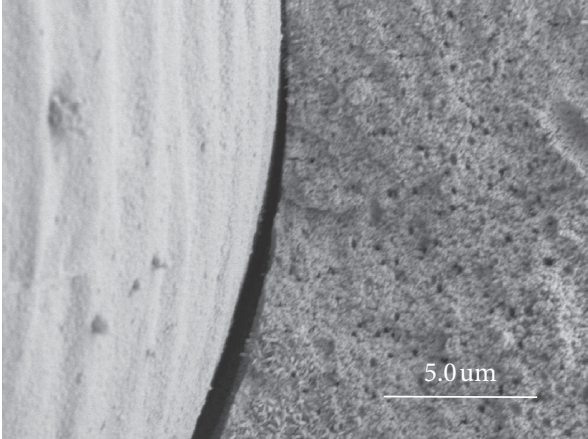

(d)

Figure 11: SEM images of the C17-1\% samples.
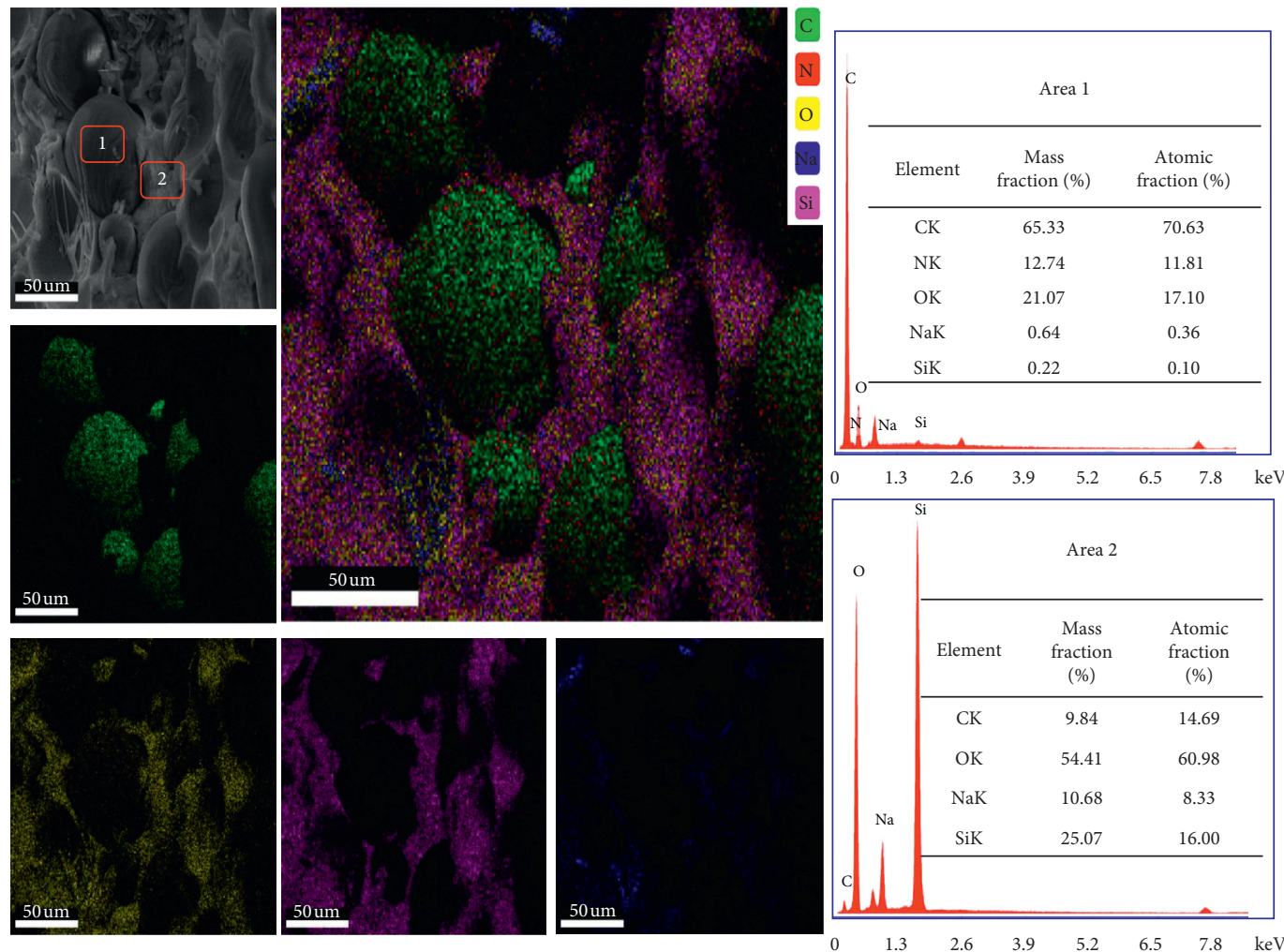

FIgURE 12: Element distribution of the C17-1\% sample.

the decomposition of polyurethane into the secondary polymer. The small difference in decomposition temperature may be caused by the different particle sizes of the samples. As shown in Figure 13(c), there were two exothermic peaks of the $\mathrm{C} 14-1 \%$ sample before $120^{\circ} \mathrm{C}$, which was attributed to two different forms of water evaporation on the surface of the material and in the pore, and the weight loss of the two parts is $12 \%$ and $4 \%$, respectively. The total weight loss of water is $16 \%$, which is the least among the three samples, probably because more water was consumed during the reaction of isocyanate with water to release $\mathrm{CO}_{2}$. The decomposition temperature of the $\mathrm{C} 14-1 \%$ sample is $336^{\circ} \mathrm{C}$, which was much higher than that of the $\mathrm{C} 7-1 \%$ and $\mathrm{C} 17-1 \%$ samples, which is due to the formation of the polymer with higher thermal stability by strong foaming catalysis.

3.5. Mechanical Properties. As the structure determines the performance, the three samples with different structures are bound to have different compressive strengths, and the mechanical results are shown in Table 2 and Figure 14. The C7-1\% sample broke when the compression deformation reached $30 \%$, and the compressive strength was $43.2 \mathrm{MPa}$, which indicated that the $\mathrm{C} 7-1 \%$ sample had higher rigidity and toughness. On the contrary, both C14-1\% and C17-1\% samples are brittle. The deformation of the C14-1\% and C17- 


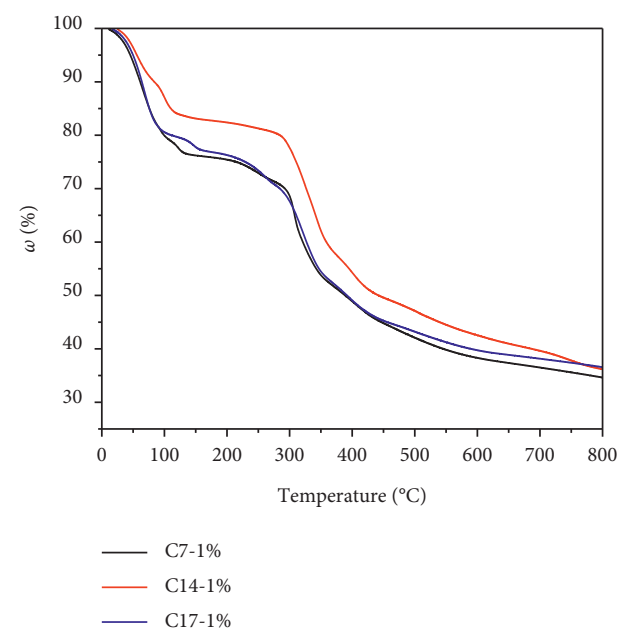

(a)

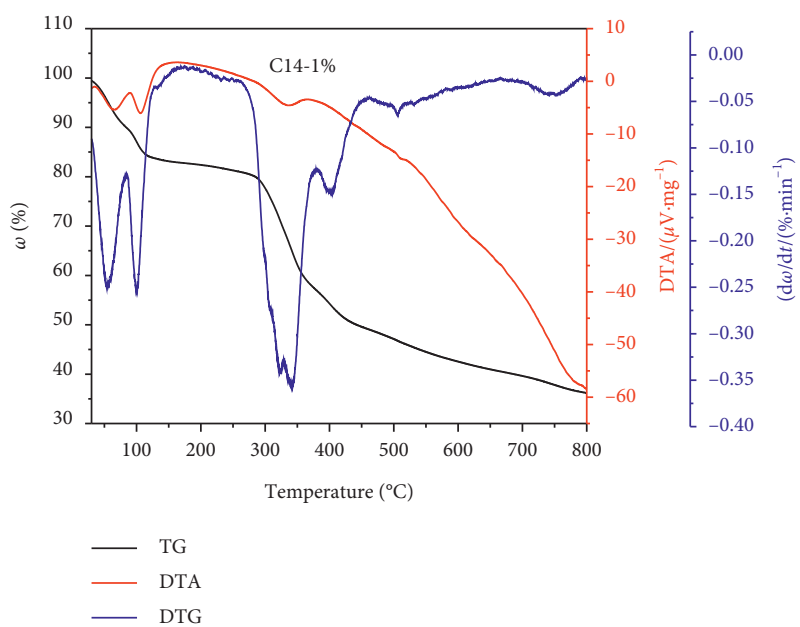

(c)

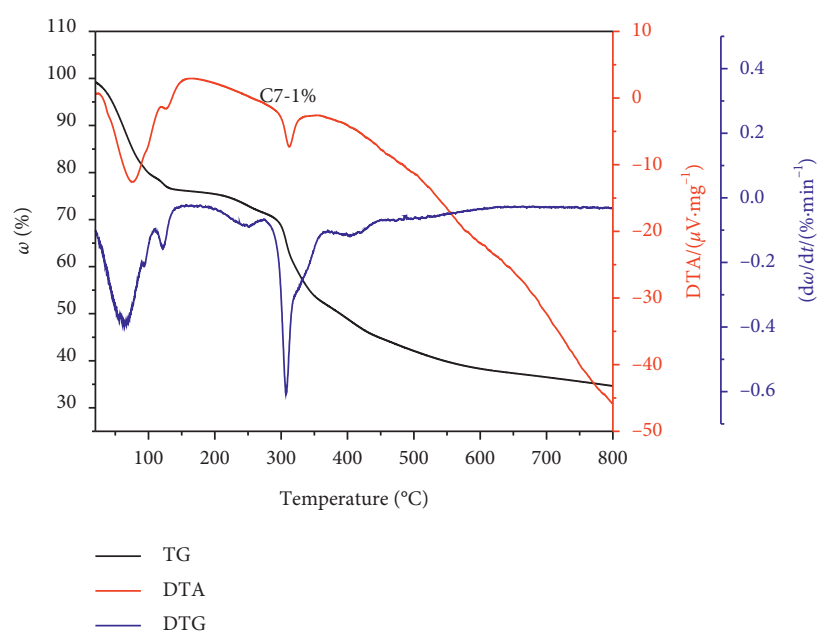

(b)

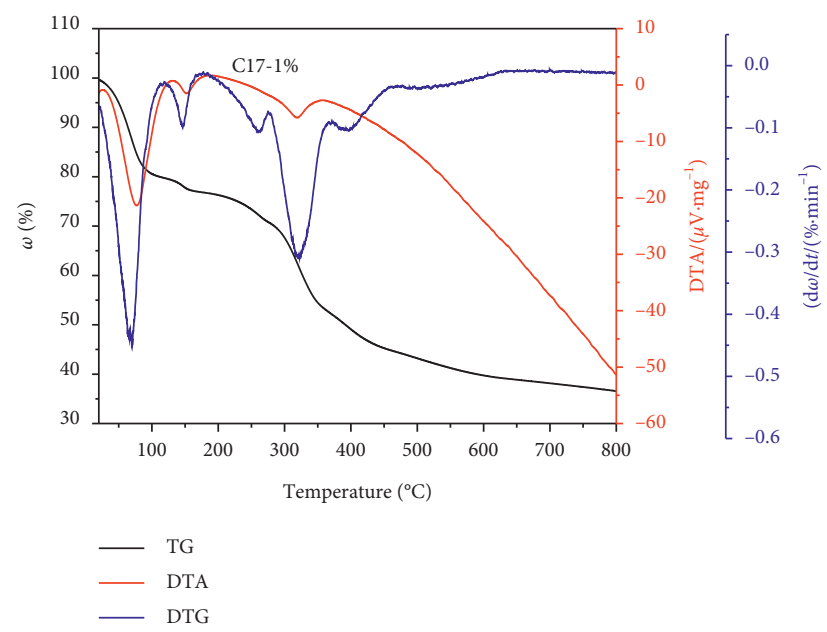

(d)

Figure 13: (a) TG curves of the three samples; TG, DTA, DTG curve of the C7-1\% (b), C14-1\% (c), and C17-1\% (d) samples.

TABLE 2: Average value and standard deviation of compressive strength of the sample.

\begin{tabular}{lccccc}
\hline Sample & \multicolumn{3}{c}{$\begin{array}{c}\text { Compressive } \\
\text { strength }(\mathrm{MPa})\end{array}$} & $\begin{array}{c}\text { Average value } \\
(\mathrm{MPa})\end{array}$ & Standard deviation \\
\hline $\mathrm{C} 7-1 \%$ & 42.6 & 43.2 & 44.0 & 43.3 & 0.5735 \\
$\mathrm{C} 14-1 \%$ & 2.3 & 2.8 & 3.0 & 2.7 & 0.2944 \\
$\mathrm{C} 17-1 \%$ & 5.5 & 5.0 & 4.2 & 4.9 & 0.5354 \\
\hline
\end{tabular}

$1 \%$ samples is only $3 \%-5 \%$ when the compressive strength of the material reached a peak value, and the average compressive strengths of the two samples are $2.7 \mathrm{MPa}$ and 4.9 Mpa, respectively. Compared with $\mathrm{C} 7-1 \%$, the compressive strength of $\mathrm{C} 17-1 \%$ was reduced by $88.6 \%$, mainly because the polymer phase in the $\mathrm{C} 17-1 \%$ sample was stored in the continuous phase composed of inorganic components in the form of microspheres, while the polyurethane continuum was formed in the C7-1\% sample, which had strong pressure bearing capacity as a rigid skeleton.

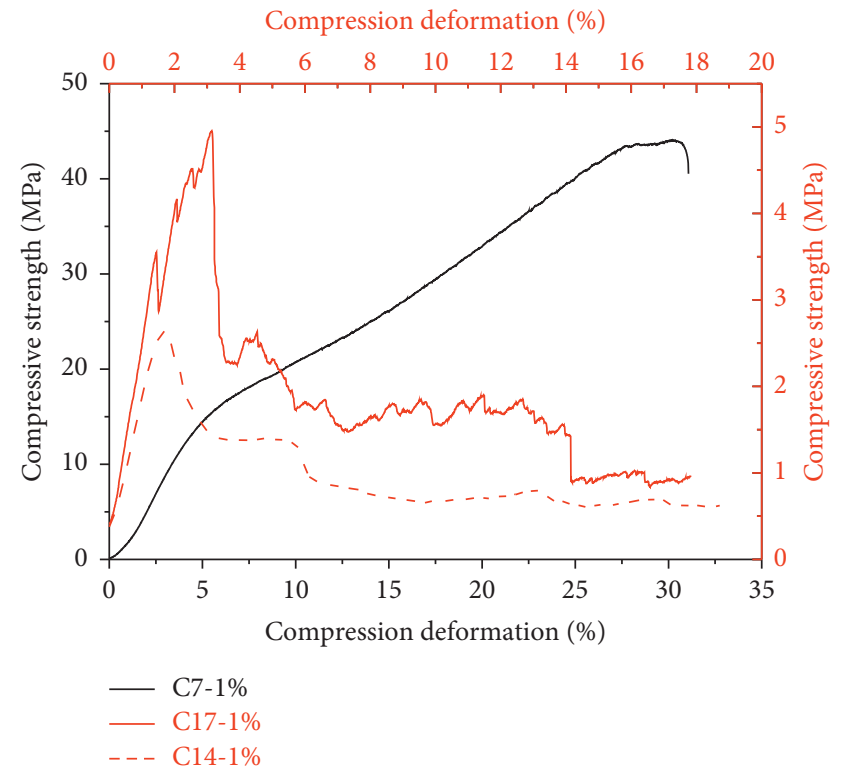

FIGURE 14: The compressive strength curves of the three samples. 


\section{Conclusions}

In conclusion, three kinds of PU/WG grouting materials with different curing behaviors were successfully prepared by changing the catalyst, and the structure, thermal stability, and compressive strength of the three samples were compared. The main conclusions are as follows:

(1) Carbonate is the main precipitate in the process of drainage.

(2) The foaming and drainage behaviors changed the material composition. The normal sample was composed of silicate polymer microspheres, sodium carbonate needle crystal, and polyurethane continuum; there were only $\mathrm{Si}-\mathrm{O}$ and no $\mathrm{Si}-\mathrm{C}$ bond in the structure; and the valence state of $\mathrm{Si}$ was +4 . There were small pieces and rod-shaped crystals on the porous surface of the foamed sample. In addition, the organic polymer in the drainage sample was embedded in the inorganic component in the form of the microsphere.

(3) The foaming and drainage behaviors had little effect on the thermal stability of the system, while the water content in the structure was different.

(4) The normal sample possessed excellent compressive strength, up to $43 \mathrm{MPa}$. However, the foaming and drainage behaviors led to a significant reduction of the compressive strength, with a reduction of more than $85 \%$.

\section{Data Availability}

The data are available on request due to privacy or ethical restrictions.

\section{Additional Points}

(1) Polyurethane/water glass samples with different curing behaviors were successfully prepared by adjusting catalysts. (2) The structural characteristics of three kinds of polyurethane/water glass composite grouting materials were analyzed by multiple characterization methods. (3) The foaming and drainage behaviors had little influence on the thermal stability of the grouting material, but they greatly reduced the compressive strength of the material.

\section{Conflicts of Interest}

The authors declare no conflicts of interest.

\section{Acknowledgments}

This research was funded by Youth Funds for China Coal Technology and Engineering Group (Grant no. 2019-TDQN022).

\section{References}

[1] Y. Fei, S. Q. Liu, Y. C. Xu, and L. Zhao, "Failure analysis of thin bedrock and clay roof in underground coal mining: case study in Longdong coal mine," International Journal of Geomechanics, vol. 20, no. 10, Article ID 04020187, 2020.

[2] W. Li, Y. C. Ye, and Q. H. Wang, "Fuzzy risk prediction of roof fall and rib spalling: based on FFTA-DFCE and risk matrix methods," Environmental Science \& Pollution Research, vol. 27, pp. 8536-8547, 2020.

[3] J. Wu, W. Zhou, H. Tao et al., "Research on failure characteristics and zoning control technology of thick-soft surrounding rock for deep gob-side entry retaining," Shock and Vibration, vol. 202014 pages, 2020.

[4] F. T. Wang, C. Zhang, and S. F. Wei, "Whole section anchorgrouting reinforcement technology and its application in underground roadways with loose and fractured surrounding rock," Tunnelling and Underground Space Technology, vol. 51, pp. 133-143, 2016.

[5] S. Hideki, H. Akihiro, and S. Takashi, "Behaviour of grouting material used for floor reinforcement in underground mines," International Journal of Mining, Reclamation and Environment, vol. 28, pp. 133-148, 2014.

[6] J. Zhang and Y. Sun, "Experimental and mechanism study of a polymer foaming grouting material for reinforcing broken coal mass," KSCE Journal of Civil Engineering, vol. 23, no. 1, pp. 346-355, 2019.

[7] X. F. Ao, F. L. Wang, and X. B. Zhu, "Grouting simulation and stability analysis of coal mine goaf considering hydromechanical coupling," Journal of Computing in Civil Engineering, vol. 31, no. 3, Article ID 04016069, 2017.

[8] W. Zhang, X. Zhu, S. Xu, Z. Wang, and W. Li, "Experimental study on properties of a new type of grouting material for the reinforcement of fractured seam floor," Journal of Materials Research and Technology, vol. 8, no. 6, pp. 5271-5282, 2019.

[9] S. Yang, M. Li, G. Song, Y. Yang, and F. Xie, "Optimization of face flexible bolting and grouting technology for longwall face support under difficult geological conditions," Energy Science \& Engineering, vol. 8, no. 4, pp. 1260-1270, 2020.

[10] Z. D. Sun, J. X. Zhang, and Y. N. Sun, "Feasibility of a polymer foaming agent as a grouting material for broken coal masses," Advances in Civil Engineering, vol. 20199 pages, 2019.

[11] B. Song, S. Zhang, and D. S. Zhang, "Inorganic cement grouting for reinforcing triangular zone of highly gassy coal face with large mining height," Energies, vol. 11, no. 10, p. 2549, 2018.

[12] X. Zhu, Q. Zhang, W. Zhang, J. Shao, Z. Wang, and X. Wu, "Experimental study on the basic properties of a green new coal mine grouting reinforcement material," ACS Omega, vol. 5, no. 27, pp. 16722-16732, 2020.

[13] Z. J. Hong, J. P. Zuo, Z. H. Zhang, C. Liu, L. Liu, and H. Y. Liu, "Effects of nano-clay on the mechanical and microstructural properties of cement-based grouting material in sodium chloride solution," Construction and Building Materials, vol. 245, Article ID 118420, 2020.

[14] G. Hamza, "On the viscous behavior of cement mixtures with clay, sand, lime and bottom ash for jet grouting," Construction and Building Materials, vol. 93, pp. 891-910, 2015.

[15] Y. J. Zhang, S. G. Wang, and B. Zhang, "A preliminary investigation of the properties of potassium magnesium phosphate cement-based grouts mixed with fly ash, water glass and bentonite," Construction and Building Materials, vol. 273, pp. 891-910, 2020.

[16] G. L. Yuan, Z. Y. Zhao, and Q. T. Li, "Bond behavior between cement-based grouting material and steel bar under repetitive loading after being exposed to high temperature at early age," Construction and Building Materials, vol. 262, Article ID 120023, 2020. 
[17] J. Zhang, S. C. Li, and Z. F. Li, "Properties of red mud blended with magnesium phosphate cement paste: feasibility of grouting material preparation," Construction and Building Materials, vol. 260, Article ID 119704, 2020.

[18] C. Zhang, B. Shuai, S. Jia et al., "Plasma-functionalized graphene fiber reinforced sulphoaluminate cement-based grouting materials," Ceramics International, vol. 47, no. 11, pp. 15392-15399, 2021.

[19] J. Zhang, X. Guan, H. Li, and X. Liu, "Performance and hydration study of ultra-fine sulfoaluminate cement-based double liquid grouting material," Construction and Building Materials, vol. 132, pp. 262-270, 2017.

[20] J. Pei, J. Cai, D. Zou et al., "Design and performance validation of high-performance cement paste as a grouting material for semi-flexible pavement," Construction and Building Materials, vol. 126, pp. 206-217, 2016.

[21] F. Zhou, W. B. Sun, and J. L. Shao, "Experimental study on nano silica modified cement base grouting reinforcement materials," Geomechanics and Engineering, vol. 20, pp. 67-73, 2020.

[22] J. P. Zhang, L. M. Liu, Q. H. Li et al., "Development of cementbased self-stress composite grouting material for reinforcing rock mass and engineering application," Construction and Building Materials, vol. 201, pp. 314-327, 2019.

[23] J. Li, J. W. Zhang, and S. Chen, "Study on dynamic viscoelastic properties and constitutive model of non-water reacted polyurethane grouting materials," Measurement, vol. 176, Article ID 109115, 2021.

[24] H. Wu, M. Zhu, Z. Liu, and J. Yin, "Developing a polymerbased crack repairing material using interpenetrate polymer network (IPN) technology," Construction and Building Materials, vol. 84, pp. 192-200, 2015.

[25] J. J. Zeng and H. J. Chen, "Preparation and properties of fast curing epoxy resin grouting materials," China Plastics, vol. 34, pp. 6-11, 2020.

[26] Z. H. Su, Z. Q. Wang, and D. Zhang, "Study on rheological behavior and surface properties of epoxy resin chemical grouting material considering time variation," Materials, vol. 12, no. 20, p. 3277, 2019.

[27] Y. Zhang, H. Pang, D. Wei et al., "Preparation and characterization of chemical grouting derived from lignin epoxy resin," European Polymer Journal, vol. 118, pp. 290-305, 2019.

[28] X. Zhang, X. Lu, L. Qiao, L. Jiang, T. Cao, and Y. Zhang, "Developing an epoxy resin with high toughness for grouting material via co-polymerization method," E-Polymers, vol. 19, no. 1, pp. 489-498, 2019.

[29] C. Zhang, J. S. Yang, J. Y. Fu et al., "Optimal formulation design of polymer-modified cement based grouting material for loose deposits," Construction and Building Materials, vol. 261, Article ID 120513, 2020.

[30] Y. Y. Chu, X. F. Song, and H. X. Zhao, "Water-swellable, tough, and stretchable inorganic-organic sulfoaluminate cement/polyacrylamide double-network hydrogel composites," Journal of Applied Polymer Science, vol. 136, no. 35, Article ID 47905, 2019.

[31] S. J. Xu, S. J. Wang, and Y. H. Zhong, "Compression characteristics and constitutive model of low-exotherm modified polyurethane grouting materials," Advances in Civil Engineering, vol. 20209 pages, 2020.

[32] Z. He, Q. Li, J. Wang, N. Yin, S. Jiang, and M. Kang, "Effect of silane treatment on the mechanical properties of polyurethane/water glass grouting materials," Construction and Building Materials, vol. 116, pp. 110-120, 2016.
[33] Q. Zhang, X. M. Hu, M. Y. Wu, Y.Y. Zhao, and C. Yu, "Effects of different catalysts on the structure and properties of polyurethane/water glass grouting materials," Journal of Applied Polymer Science, vol. 135, pp. 1-11, 2018.

[34] A. Atiqah, M. Mastura, B. Ali, M. Jawaid, and S. Sapuan, "A review on polyurethane and its polymer composites," Current Organic Synthesis, vol. 14, no. 2, pp. 233-248, 2017.

[35] M. L. Xu, X. F. He, and J. F. Li, "Research on application of polyurethane grouting material for mining," Materials Review, vol. 28, pp. 96-100, 2014.

[36] GB/T 2567-2008, Chinese Specification, Test Methods for Properties of Resin Casting Body, Chinesestandard.net, Beijing, China, 2008. 